\title{
Small Aquatic Duckweed Plants with Big Potential for the Production of Valuable Biomass and Wastewater Remediation
}

\author{
Yuzhen Zhou and Nikolai Borisjuk* \\ Jiangsu Collaborative Innovation Center of Regional Modern Agriculture \& Environmental Protection, the School of Life Sciences, Huaiyin Normal \\ University, China
}

Submission: December 17, 2018; Published: January 22, 2019

*Corresponding author: Nikolai Borisjuk, Jiangsu Collaborative Innovation Center of Regional Modern Agriculture \& Environmental Protection, the School of Life Sciences, Huaiyin Normal University, Huaian, China

\section{Mini Review}

Pollution and shortages in clean water supplies are some of the most serious problems that humanity is facing. In many Asian countries and elsewhere, the demand for potable water doubles every 10-15 years due to rising domestic consumption and the increasing needs of industry $[1,2]$. Eutrophication of municipal and industrial water reservoirs is a global concern and has been identified as a major environmental problem for water resource management. Furthermore, about 80 million tons of nitrogen fertilizers are applied globally per year to maximize yield [3], and no more than $40 \%$ of this amount is taken up by crops [4]. The rest of the chemicals eventually end up in the fresh water reservoirs on their way to the ocean. The excess of agrochemical fertilizersprimarily nitrogen $(\mathrm{N})$ and phosphorus $(\mathrm{P})$ - are considered as the major causes of eutrophication. Another source of water pollutant is the nutrients used in the fast-growing aquaculture systems. The main contaminants from aquaculture wastewater effluent are ammonium, organic N, and P [5]. Only about $15 \%$ of $\mathrm{N}$ and $25 \%$ of $P$ from aquaculture feed are assimilated by fish and shrimps, and the unutilized part accumulates in the water or in the sediment [6]. The eutrophication of water bodies due to aquaculture wastewater has been sharply rising during the last 20 years at a rate of $2-4 \%$ per year in the Yangtze River Basin and Zhujiang Delta Basin [6].

The need to reduce anthropogenic nutrients in aquatic ecosystems to prevent water eutrophication has been widely recognized [7]. A number of physical, chemical, and biological methods used in wastewater treatment have been tested. As the eco-friendliest method, the cultivation of aquatic plants is attractive for the restoration of eutrophic water bodies by nutrient removal, accumulating toxic nutrients and heavy metals, and regulating oxygen balance [8]. Duckweed is a group of small aquatic plants with high growth rates that often completely cover the surface of a water body (Figure 1). Its productivity can reach 80-100 tons of dry mass per hectare per year, which is over 5 times as high as maize [9]. In the process of biomass accumulation, duckweed can very efficiently remediate different types of wastewater [10]. These complementary features of water remediation and fast biomass accumulation have made duckweed a subject of intense global research interest in recent years $[9,11]$. This mini-review highlights the numerous benefits that these tiny plants can provide.

\section{Duckweed, an efficient global wastewater remediator}

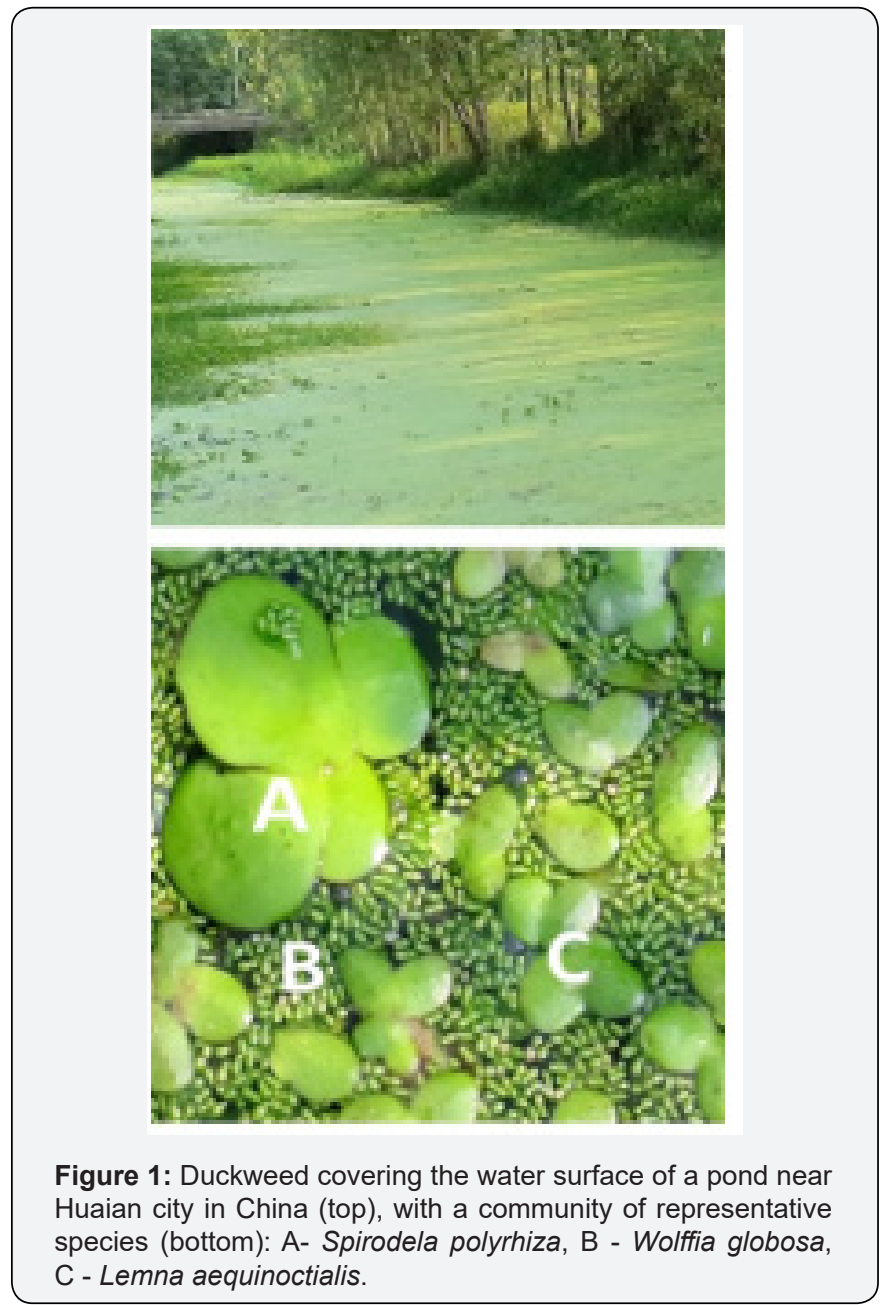



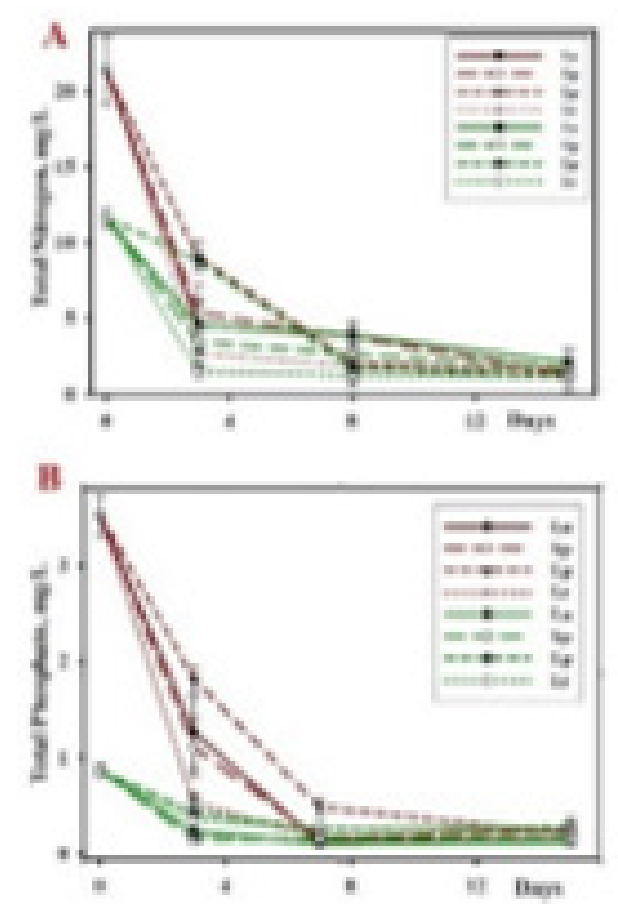

Figure 2: Removal of total nitrogen (A) and total phosphate (B) from municipal wastewater by four duckweed species. Red lines refer to duckweeds cultivated in influent wastewater, and the green lines refer to duckweeds cultivated in effluent wastewater. La: L. aequinoctialis; Sp: S. polyrhiza; Lp: L. punctata; Lt: L. turionefera.

Various aquatic plants have been tested for the bioremediation of wastewater based on their specific physiological features, high growth rates, and simple maintenance. Special attention has been paid to plants in the Lemnaceae family, which are commonly known as duckweeds. This family of monocotyledonous aquatic plants contains five genera: Lemna, Spirodela, Wolffia, Wolffiela, and Landoltia [12]. There are 37 species distributed around the globe [13]. Floating aquatic duckweeds are the most morphologically reduced form of all flowering plants. The largest of these species, Spirodela polyrhiza, has fronds of about $5 \mathrm{~mm}$, and the smallest species, Wolffia, does not exceed $1 \mathrm{~mm}$ (Figure 1). Duckweeds are widely distributed geographically, and most species are primarily tropical or subtropical, but others occur in temperate regions. Due to their aquatic lifestyle, duckweed species can rapidly remove nitrogen and phosphorous from anthropogenic waste streams. Duckweed can accumulate up to $9.1 \mathrm{t} / \mathrm{ha}$ /year of total nitrogen and $0.8 \mathrm{t} / \mathrm{ha}$ /year of total phosphorus in their biomass. Our experiments have demonstrated that after just 3 days of incubation of the duckweed Lemna turionefera in local municipal wastewater, the main nutrient concentrations (total nitrogen and total phosphate) were lower than those in the effluent from a local wastewater treatment plant (Figure 2) [14]. With 15 days of growth, four duckweed species were able to remove more than $93 \%$ of both total nitrogen and total phosphate in local municipal wastewater (Figure 2) [14]. The final total nitrogen concentration was of $1 \mathrm{mg} / \mathrm{L}$, which is much lower than the national standard for treated wastewater $(1.5 \mathrm{mg} / \mathrm{L}$, China Standard GB 189182002) and is close to the total nitrogen level accepted for drinking water(1.5 mg/L, China Standard GB3838-2002).

Similarly, high rates of removal were also demonstrated with duckweed growing on sewage water [15] and wastewater from a hog farm [16]. Moreover, 98\% removal of N and P from pig-farm effluent has been achieved [17]. This was accompanied by a significant increase in the level of dissolved oxygen and the production of duckweed biomass with $35 \%$ crude protein [17]. Another advantage of duckweed is its tolerance of relatively high concentrations of ammonia $\left(\mathrm{NH}_{4}^{+}\right)$, which is toxic to plants, animals, and humans. The common duckweed (L. minor) has been reported to grow well at $\mathrm{NH}_{4}{ }^{+}$concentrations of up to $84 \mathrm{mg} / \mathrm{L}$ [18]. The ability of duckweeds to take up and tolerate such high levels of $\mathrm{NH}_{4}^{+}$makes the plants particularly suited to the remediation of wastewater from domestic and agricultural sources, which often contain considerable amounts of this ion.

Due to these specific features, duckweed is considered as a low-cost wastewater-treatment platform that efficiently accumulates water contaminants such as remaining $\mathrm{N}$ and $\mathrm{P}$ fertilizers [19]. In addition, it also has potential for monitoring and remediating heavy metals [10]. Heavy metals are released into the environment from both natural and anthropogenic sources, predominantly from mining and industrial activities. Duckweed is relatively tolerant and able to take up many heavy metal ions, including $\mathrm{Cu}, \mathrm{Fe}, \mathrm{Zn}, \mathrm{Cr}, \mathrm{Cd}, \mathrm{Pd}, \mathrm{Pb}, \mathrm{Ni}$, and $\mathrm{As}$. Thus, it is being used for the heavy-metal phytoremediation of aquatic ecosystems [20].

\section{Duckweed as a renewable source of valuable biomass}

In addition to its abilities to clean wastewater, the current renewed interest in duckweeds [11] is driven by its potential as a promising platform for the production of valuable biomass [21]. Because of its high growth rate, low lignin content, and high starch content, duckweed is regarded as a promising renewable feedstock for biofuel [22]. With a doubling time of about 24 hours for some species, duckweed is the fastest-growing flowering plant and has an annual biomass productivity of 39-105 tons of dry weight per hectare per year [10]. For comparison, the productivity of Miscanthus, a major bioenergy grass, is 5-44 t DW/ha/year. A high percentage of starch (up to $50 \%$ dry weight) can be obtained in some strains under some growth conditions [16]. Along with the low amount of lignin $(<5 \%)$, this makes duckweed a quite competitive system compared to other plants being considered for the biomass production of fuel alcohols. Duckweed can also yield about $50 \%$ more ethanol per hectare than maize, a standard ethanol crop in the US [22]. Additionally, because of its aquatic lifestyle, duckweed does not compete with crops for arable land, and its floating biomass allows for rapid, low-energy input collection for further processing. To obtain biofuel, the biomass of duckweed could be directly fermented into ethanol/butanol or converted into bio-oils by pyrolysis [23].

A number of recent studies have demonstrated that some duckweed species have excellent nutrition qualities both for 
animal and human nutrition [24-25]. It can easily be observed that various animals, such as ducks, geese, and fish, naturally feed on duckweeds. Furthermore, duckweed is instinctively used for feeding domesticated animals, either by providing them with access to natural vegetation or by supplementing the diet with harvested duckweed in both fresh and dry forms. In some Asian countries, duckweed is also used as food for humans. For example, fresh Wolffia plants are used to prepare salads, omelets, or vegetable curries in some countries [26]. Recognizing the nutrition value combined with the extremely fast grow of Wolffia, the Israeli company GreenOnyx advertises a small machine for growing Wolffia, which can be used to prepare fresh juice or salad at home (www.greenonyx.biz). Soybean is currently the most important and preferred source of vegetable protein for animal and fish feed.

However, duckweed species have an average of $30.0 \%$ crude protein, which is close to the protein contents yielded by soybean (between 33 and 49\%). With high contents of protein and starch, duckweed can be used as viable source to produce feed and as feed supplement for animals. Many studies have been carried on animals such as fishes, dairy cows, pigs, sheep, goats, and poultry, which have shown that protein intake can be partially or completely substituted by duckweed without impeding growth $[16,27]$.

Fish feed is the most widespread use of this plant since it can be used in a green state and is very suitable for both herbivorous and omnivorous animals [28]. Generally, protein feed with high biological value is very expensive and cannot be supported by fish farming. Duckweed is locally available and a low-cost solution for intensive fish aquaculture [29]. Moreover, duckweed can be grown directly in the fish farm ponds or in nearby ponds that are integrated for wastewater remediation and the production of duckweed-based feed. Therefore, in addition to providing a cheap, renewable source of protein, such a multi-trophic aquaculture system could serve to bio-recuperate waste nutrients produced during fish cultivation from aquaculture wastewater, which would increase economic efficiency and minimize the negative effects on the environment.

As an alternative to inorganic fertilizers, green manure is an attractive option to increase soil fertility and can provide substantial benefits for farmers. General studies of green manure are mainly focused on leguminous plants, and very limited information is available regarding duckweed as green manure, despite its easy availability and substantial biomass accumulation in certain areas. Yao showed that urea combined with duckweed cover reduced $\mathrm{NH}_{3}$ loss by 36-52\% and increased nitrogen accumulation in ground plants by $14-25 \%$ compared to the control over a 3-year test period [30]. This resulted in 9-10\% higher rice yield and $10-11 \%$ higher net economic benefit compared to the control. Thus, duckweed as green manure combined with chemical fertilizer application provides an approach for increasing the rice yield without increasing the inputs of nitrogen fertilizer. This could provide a financially attractive option for farmers to achieve environmental integrity and ensure food security in rice production.

\section{Conclusion}

Duckweed features environmental remediation capabilities and potential as an efficient feedstock for fuel and bioproducts. Thus, we believe the continual acceptance and optimization of duckweed farming will make the system a valuable integrative part of the modern cycling economy. Its success will benefit many important areas of human activities, including water resources, renewable energy, agriculture practices, and food production.

\section{Acknowledgements}

This research work was partially funded by individual grant awarded to NB and YZ from the Huaiyin Normal University, Huaian, China and the Jiangsu Natural Science Foundation grant, BK20131213, awarded to YZ.

\section{References}

1. Priya A, Avishek K, Pathak G (2012) Assessing the potentials of Lemna minor in the treatment of domestic wastewater at pilot scale. Environ Monit Assess 184(7): 4301-4307.

2. Srivastava J, Gupta A and Chandra H (2008) Managing water quality with aquatic macrophytes. Revised Environ Sci Technol 77: 255-266.

3. (2014) FAO. Statistical Databases. Food and Agriculture Organization of the United Nations.

4. Sylvester-Bradley R, Kindred DR (2009) Analysing nitrogen responses of cereals to prioritize routes to the improvement of nitrogen use efficiency. J Exp Bot 60(7): 1939-1951.

5. Cao L, Wang W (2010) Wastewater management in freshwater pond aquaculture in China. In: Sumi A, Fukushi K, Honda R and Hassan KM, Sustainability in Food and Water: an Asian Perspective, Springer, Dordrecht pp. 181-190.

6. He F, Wu Z (2003) Application of aquatic plants in sewage treatment and water quality improvement. Chin Bull Botany 20(6): 641-647.

7. Conley DJ, Paerl HW, Howarth RW, Boesch DF, Seitzinger SP, et al. (2009) Controlling eutrophication by reducing reducing both nitrogen and phosphorus. Sci 323: 1014-1015.

8. Dhote S, Dixit S (2009) Water Quality improvement macrophytes-a review. Environ Monit Assess 152(1-4): 149-153.

9. Lam E, Appenroth KJ, Michael T, Mori K, Fakhoorian T (2014) Duckweed in bloom: the $2^{\text {nd }}$ International Conference on Duckweed Research and Applications heralds the return of a plant model for plant biology. Plant Mol Biol 84: 737-742.

10.Ziegler P, Sree KS, Appenroth K (2016) Duckweeds for water remediation and toxicity testing. Toxicol Environ Chem 98(10): 11271154.

11. Appenroth KJ, Sree KS, Fakhoorian T, Lam E (2015) Resurgence of duckweed research and applications: report from the $3^{\text {rd }}$ International Duckweed Conference. Plant Mol Biol 89(6): 647-54.

12. Appenroth KJ, Borisjuk N, Lam E (2013) Telling duckweed apart: genotyping technologies for the Lemnaceae. Chin J Appl Environ Biol 19(1): 1-10.

13. Les DH (2002) Phylogeny and systematics of Lemnaceae, the duckweed family. Syst Bot 13: 221-240.

14. Zhou Y, Chen G, Peterson A, Zha X, Cheng J, et al. (2018) Biodiversity of duckweeds in Eastern China and their potential for bioremediation of 
municipal and industrial wastewater. J Geosci Environ Prot 6(3):108116

15. Yu CJ, Sun CJ, Yu L, Zhu M, Xu H, et al. (2014) Comparative analysis of duckweed cultivation with sewage water and $\mathrm{SH}$ media for production of fuel ethanol. PLOS ONE 9: 1-15.

16. Cheng JJ, Stomp AM (2009) Growing duckweed to recover nutrients from wastewaters and for production of fuel ethanol and animal feed. Clean-Soil Air Water 37(1): 17-26.

17. Mohedano RA, Costa RHR, Tavares FA, Belli FP (2012) High nutrient removal rate from swine wastes and protein biomass production by full-scale duckweed ponds. Bioresour Technol 112: 98-104.

18. Zhang K, Chen YP, Zhang TT, Zhao Y, Shen Y, et al. (2014) The logistic growth of duckweed (Lemna minor) and kinetics of ammonium uptake. Environ Tech 35(5-8): 562-567.

19. Cui W, Cheng JJ (2015) Growing duckweed for biofuel production: a review. Plant Biol 17(Suppl 1): 16-23.

20. Rai PK (2009) Heavy metal phytoremediation from aquatic ecosystems with special reference to macrophytes. Crit Rev Environ Sci Technol 39(9): 697-753.

21. Zhao Y, Fang Y, Jin Y, Huang J, Bao S, et al. (2014) Potential of duckweed in the conversion of wastewater nutrients to valuable biomass: a pilotscale comparison with water hyacinth. Bioresour Technol 63: 82-91.

22. Xu JL, Cui WH, Cheng JJ, Stomp AM (2011) Production of high-starch duckweed and its conversion to bioethanol. Biosyst Eng 110(2): 67-72.

23. Muradov N, Taha M, Miranda AF, Kadali K, Gujar A, et al. (2014) Dual application of duckweed and azolla plants for wastewater treatment and renewable fuels and petrochemicals production. Biotechnol Biofuels 7: 30-45.

24. Appenroth KJ, Sree KS, Böhm V, Hammann S, Vetter W, et al. (2017) Nutritional value of duckweeds (Lemnaceae) as human food. Food Chem 217: 266-273.

25. Appenroth KJ, Sree KS, Bog M, Ecker J, Seeliger C, et al. (2018) Nutritional value of the duckweed species of the genus Wolffia (Lemnaceae) as human food. Front Chem 6: 483.

26. Saengthongpinit W (2017) Indigenous cuisine with a modern flare. Duckweed Forum 5: 8.

27. Xu J, Cheng JJ, Stomp AM (2012) Growing spirodela polyrrhiza in swine wastewater for the production of animal feed and fuel ethanol: a pilot study. CLEAN-Soil Air Water 40(7): 760-765.

28. Iqbal S (1999) Duckweed aquaculture. potentials, possibilities and limitations for combined wastewater treatment and animal feed production in developing countries. SANDEC Report No. 6/99.

29. Leng RA, Stambolie JH, Bell R (1995) Duckweed-a potential highprotein feed resource for domestic animals and fish. Livestock Res Rural Dev 7(1): 36.

30. Yao Y, Zhang M, Tian Y, Zhao M, Zhang B, Zhao M, Zeng K, Yin B (2017) Duckweed (Spirodela polyrhiza) as green manure for increasing yield and reducing nitrogen loss in rice production. Field Crops Res 214: 273-282. 